\section{MS19-P3 Polyoxometalates as structurally diverse and efficient catalysts for artificial photosynthesis}

Kim D. von Allmen ${ }^{1}$, René Moré ${ }^{1}$, Greta R. Patzke*1

1. University of Zurich, Department of Chemistry B, Winterthurerstrasse 190, CH-8057 Zurich, Switzerland

email: kim.vonallmen@chem.uzh.ch

Polyoxometalates (POMs) are metal oxo clusters which are preferably formed by $\mathrm{W}$, Mo and $\mathrm{V}$ in their high oxidation states. They emerge from complex self-assembly processes and excel through an exceptionally wide range of applications. An impressive multitude of POM structure types has been reported to date, ranging from low nuclearity to nanoscale clusters. POMs are furthermore applied as highly active catalysts, e.g. for organic transformations and artificial photosynthesis, and their magnetic properties and biomedical applications are of current interest. [1]

The controlled preparation and precise crystallographic characterization of new POMs is crucial to generate libraries for screening their potential applications. We have studied the reaction of the lacunary precursor material $\mathrm{Na}_{10}\left[\alpha-\mathrm{SiW}_{9} \mathrm{O}_{34}\right] \bullet 15 \mathrm{H}_{2} \mathrm{O}\left(\mathbf{S i W}_{9}\right)$ with $\mathrm{Ga}(\mathrm{III})$ ions in aqueous solution. The emerging new crystal structures

$\mathrm{K}_{10}\left[\mathrm{Ga}_{6}\left(\mathrm{H}_{2} \mathrm{O}\right)_{3}\left\{\alpha-\mathrm{SiW}_{9} \mathrm{O}_{35}(\mathrm{OH})_{2}\right\}_{2}\right] \bullet 35.5 \mathrm{H}_{2} \mathrm{O} \quad(\mathbf{G a}-\mathbf{1})$ and $\mathrm{K}_{12}^{6}\left[\mathrm{Ga}_{4}\left(\mathrm{H}_{2} \mathrm{O}\right)_{2}\left\{\alpha-\mathrm{SiW}_{10} \mathrm{O}_{38}\right\}_{2}\right] \bullet 30 \mathrm{H}_{2} \mathrm{O}^{2}(\mathbf{G a}-2)$ have been described in detail. Both compounds could be isolated in phase pure form and were characterized with a wide range of additional spectroscopic and electrochemical methods. [2]

While our structural chemistry work highlights the preparation and isolation of new Ga-containing polyoxotungstates, our most recent studies are focused on POM catalyst development. Ni-substituted POMs have been investigated as water reduction catalysts (WRC) for visible-light driven $\mathrm{H}_{2}$ evolution. [3] In order to establish structure-activity relationships (SAR), Ni-based Keggin-type POMs of the general type $\left[\mathrm{Ni}\left(\mathrm{H}_{2} \mathrm{O}\right) \mathrm{XW}_{11} \mathrm{O}_{39}\right]^{\mathrm{n}-}(\mathrm{X}=\mathrm{P}, \mathrm{Ge}, \mathrm{Si})$ have been crystallized and characterized by $\mathrm{X}$-ray crystallographic methods. All three compounds have been tested as WRCs in an established photochemical assay for visible-light driven $\mathrm{H}_{2}$ evolution, and the heteroatom was found to have an important influence on their $\mathrm{H}_{2}$ evolution activity. In order to understand and explain the observed trends, electrochemical experiments and DFT calculations have been performed.

[1] J. R. Poeppelmeier, Comprehensive Inorganic Chemistry 5II6, Second Edition ed., Elsevier, Amsterdam, 2013. [2] K. von Allmen, P.-E.Car, O. Blacque, T. Fox, R. Müller, G. R. Patzke, Z. Anorg. Allg. Chem. 2014, 640, 781-789. [3] K. von Allmen, R. Moré, R. Müller, J. Soriano-López, A. Linden, G. R. Patzke, in revision.
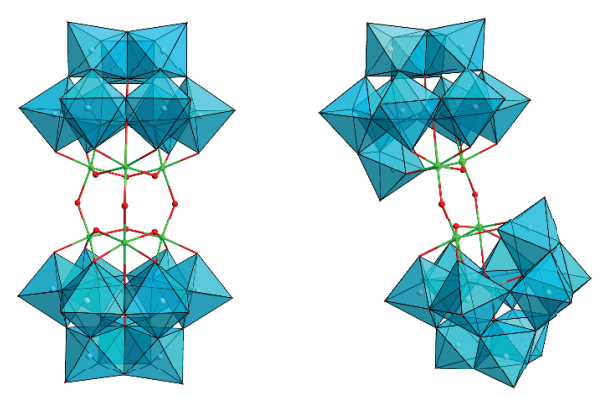

Figure 1. Polyhedral ball-and stick representation of Ga-1 (left), Ga-2 (right).

Keywords: Polyoxometalates, Artificial photosynthesis, Nickel, Gallium, Catalysis 